\title{
Four Compounds Isolated from Polygonum lanatum Roxb
}

\author{
Taslima Akter ${ }^{1}$, M. Mahboob Ali Siddiqi ${ }^{2}$, Al-Mansur M.A. ${ }^{4}$, M. H. Sohrab ${ }^{4}$, \\ A. M. Sarwaruddin Chowdhury ${ }^{1^{*}}$ and Choudhury M. Hasan ${ }^{3}$ \\ ${ }^{1}$ Department of Applied Chemistry and Chemical Engineering, Dhaka University, Dhaka-1000, Bangladesh \\ ${ }^{2}$ Institute of Natural Sciences, United International University, Dhaka-1209, Bangladesh \\ ${ }^{3}$ Department of Pharmaceutical Chemistry, Dhaka University, Dhaka-1000, Bangladesh \\ ${ }^{4}$ Analytical Research Division, Bangladesh Council of Scientific and Industrial Research, Dhaka-1205, Bangladesh
}

(Received : 25 January 2012; Accepted : 2 March 2013)

\section{Introduction}

Polygonum lanatum (Bengali name-Bishkatali; FamilyPolygonaceae), a herb having anti-inflammatory, analgesic and diurectic activity ${ }^{1}$, is distributed in Southeast Asia. Previous phytochemical investigations with Polygonum species led to the isolation of sterols $^{2}$, terpenoids ${ }^{3}$, flavonoid glycosides ${ }^{4}$, coumaryl glycoside ${ }^{2}$, lignans ${ }^{5}$, quinones $^{2}$, 6-methoxyplumbagin ${ }^{6}$. Here, we report the isolation of $p$-anisaldehyde (1), 4-hydroxy benzaldehydy (2), 6-acetyl-2,3-dihydroxyanthracene-9,10-dione (3) and 2-hydroxy-3 methoxy-2,9-dimethyl-1,2 dihydrotetraphene7,12-dione (4) from the methanol extract of the stem of Polygonum lanatum Roxb.

\section{II.Materials and Methods}

General experimental procedure: The ${ }^{1} \mathrm{H}$ NMR spectra were recorded by using a Bruker AMX-400 (400 MHz) instrument. For NMR studies deuterated chloroform was used and the $\delta$ values for ${ }^{1} \mathrm{H}$ spectra were referenced to the residual nondeuterated solvent signals.

Plant Material: The fresh stem of Polygonum lanatum was collected from Chittagong. It was identified by Bangladesh National Herbarium, Dhaka (DACB-31286). All the stems were cut into small pieces and then air dried for several days. The pieces were then oven dried for 24 hours at considerably low temperature to effect grinding. The plant was then ground into a coarse powder using a grinding machine.

Extraction and Isolation: The air dried stem bark powder $(503 \mathrm{~g})$ of Polygonum lanatum was successively extracted with $n$-hexane, dichloromethane and methanol through hot extraction process with the help of soxhlet apparatus. Afterwards the extracts were filtered by suction. The filtrates were then concentrated by a Rotary evaporator, which afforded $n$-hexane $(4.25 \mathrm{~g})$, dichloromethane $(2.0 \mathrm{~g})$ and methanol $(4.0 \mathrm{~g})$ soluble materials. The methanol soluble fraction (3.5 g) was fractionated by column chromatography over silica gel (70230 mesh) eluted with $n$-hexane followed by mixture of $n$ hexane, dichloromethane and finally dichloromethane and methanol mixtures of increasing polarity to give 46 fractions collected in each $200 \mathrm{ml}$. In addition, the fractions from 5 th to 7 th taken from 46 fractions were combined and subjected to column chromatography. As a result, 44 fractions were obtained and the fractions 13-15 taken from 44 fractions were combined and further subjected to column chromatography. Furthermore, the fractions 32-38 taken from the last column chromatography were mixture and also subjected to preparative thin layer chromatography (stationary phase- silica gel $\mathrm{F}_{254}$, mobile phase $70 \%$ toluene in ethyl acetate with few drops of acetic acid, thickness of plates- $0.5 \mathrm{~mm}$ ). Finally from the developed plate, four sets of identical bands were scrapped and initially eluted with a mixture of chloroform and ethyl acetate followed by $100 \%$ ethyl acetate. Consequently evaporation of solvent afforded the four compounds.

p-Anisaldehyde (1): colored crystal; ${ }^{1} \mathrm{H}$ NMR (400 MHz, $\left.\mathrm{CDCl}_{3}\right): \delta 9.88(1 \mathrm{H}, \mathrm{s}, 1-\mathrm{CHO}), 7.84(2 \mathrm{H}, \mathrm{d}, J=9 \mathrm{~Hz}, \mathrm{H}-2$ and H-6), 7.00 (2H, d, $J=9 \mathrm{~Hz}, \mathrm{H}-3$ and H-5), 3.89 (3H, s, 4- $\mathrm{OCH}_{3}$ )

Hydroxy benzaldehyde(2): white gum; ${ }^{1} \mathrm{H}$ NMR (400 MHz, $\left.\mathrm{CDCl}_{3}\right): \delta 9.97(1 \mathrm{H}, \mathrm{s}, 1-\mathrm{CHO}), 7.82(2 \mathrm{H}, \mathrm{d}, J=8.4,2-\mathrm{H}$ and H-6), 7.35 (2H, d, $J=8.4,3-\mathrm{H}$ and $5-\mathrm{H}), 7.51(1 \mathrm{H}, \mathrm{s}, 4-$ $\mathrm{OH})$

6-Acetyl-2,3-dihydroxyanthracene-9,10-dione (3): white gum; ${ }^{1} \mathrm{H}$ NMR (400 MHz, $\left.\mathrm{CDCl}_{3}\right): \delta 7.48(1 \mathrm{H}, \mathrm{s}, \mathrm{H}-1, \mathrm{H}-2$, 2-OH, 3-H, 3-OH), 7.50 (1H, s, H-4), 8.54 (1H, d, H-5, H6), $2.62\left(3 \mathrm{H}, \mathrm{s}, 6-\mathrm{COCH}_{3}\right), 8.07(1 \mathrm{H}, \mathrm{d}, J=6.6, \mathrm{H}-7), 8.15$ (1H, d, J=6.6, H-8, H-9, H-10)

2-hydroxy-3 methoxy-2,9-dimethyl-1,2-dihydrotetraphene7,12-dione (4): white gum; ${ }^{1} \mathrm{H} \mathrm{NMR}$ (400 $\left.\mathrm{MHz}, \mathrm{CDCl}_{3}\right): \delta$ $2.72(2 \mathrm{H}, \mathrm{s}, 1-\mathrm{H}, 2-\mathrm{H}, 2-\mathrm{OH}), 2.15\left(3 \mathrm{H}, \mathrm{s}, \mathrm{H}-3,2-\mathrm{CH}_{3}\right)$, $3.62\left(3-\mathrm{OCH}_{3}\right), 5.40(1 \mathrm{H}, \mathrm{bs}, \mathrm{H}-4), 7.32(1 \mathrm{H}, \mathrm{d}, J=8.0, \mathrm{H}-$ 5), 8.0 (1H, d, J=8.0, H-6, H-7), 8.08 (1H, d, H-8), 2.34 $\left(3 \mathrm{H}, \mathrm{s}, 9-\mathrm{CH}_{3}\right), 7.65(1 \mathrm{H}, \mathrm{dd}, J=8.0, \mathrm{H}-10), 8(1 \mathrm{H}, \mathrm{d}, J=$ 8.0, H-11, H-12)

\section{III.Results and Discussion}

Compound (1) was obtained as colored crystal. It appeared as a dark quenching spot on the TLC plate under UV light at $254 \mathrm{~nm}$ and was soluble in dichloromethane and chloroform. The ${ }^{1} \mathrm{H}$ NMR spectra of compound (1) was given in the experimental part. On this basis of the NMR spectroscopic data, the compound (1) was identified as $p$ anisaldehyde.

*Author for Correspondence, e-mail: sarwar@du.ac.bd 


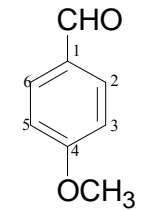

Compound (1)

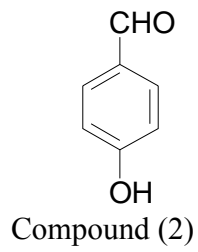

Compound (2) was obtained as colorless gummy material. It appeared as dark unclenching spots on TLC plate under UV light at $254 \mathrm{~nm}$ and was soluble in $\mathrm{CH}_{2} \mathrm{Cl}_{2}$ and $\mathrm{CHCl}_{3}$. The ${ }^{1} \mathrm{H}$ NMR spectrum of compound (2) showed signals for four methines, one aldehydic group and one hydroxyl group. The structure of compound (2) was elucidated by direct comparison of each spectral data with compound (1). Although the ${ }^{1} \mathrm{H}$ NMR spectrum of compound (2) was in close correspondence to that of compound (1), some differences could be observed, such as the resonance at $\delta=3.89$ in the ${ }^{1} \mathrm{H}$ NMR could not be observed in compound (2). On the other hand one-proton broad singlet at $\delta=7.51$ was appeared in the ${ }^{1} \mathrm{H}$ NMR spectrum of compound (2) corresponding to the 4-OH group. The ${ }^{1} \mathrm{H}$ NMR spectrum of compound (2) showed two symmetric pairs of coupled of two doublets at $\delta 7.82(\mathrm{H}-2$ and H-6) and at $\delta-7.35(\mathrm{H}-3$ and $\mathrm{H}-5$ ) assigning to a 1,4-disubsituted benzene ring present in compound (2). The presence of sharp one proton singlet at $\delta=9.97$ could be attributed to one aldehydic group.

So it is clear from all of these ${ }^{1} \mathrm{H}$ NMR signals that the aldehydic and hydroxyl groups are the substituents at C-1 and C-4, respectively, of the 1,4-disubsituted benzene ring. On this basis compound (2) was identified as 4-hydroxy benzaldehyde.

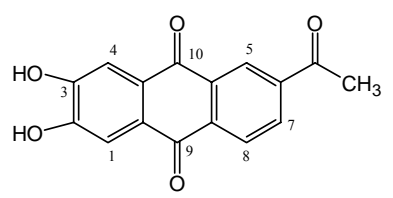

Compound (3)

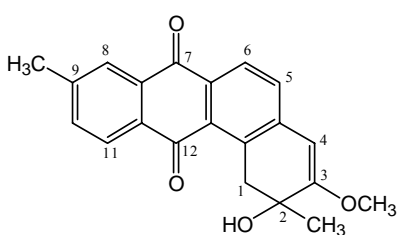

Compound (4)
Compound (3) was obtained as pink gum. It appeared as a dark quenching spot on the TLC plate under UV light at $254 \mathrm{~nm}$ and was soluble in $\mathrm{CH}_{2} \mathrm{Cl}_{2}$ and $\mathrm{CHCl}_{3}$. The ${ }^{1} \mathrm{H}$ NMR (400 MHz, $\mathrm{CDCl}_{3}$ ) spectrum of compound (3) has shown general features of substituted anthraquinone system. The ${ }^{1} \mathrm{H}$ NMR spectrum has shown two singlets integrating for one proton each at $\delta=7.48$ and $\delta=7.50$ indicated a typical 1,2,4,5-tetra substituted aromatic ring and the position of the two singlet at $\delta=7.48$ and $\delta=7.50$ could be attributed to the two protons of C-1 and C-4 respectively. The two dublets $(J=6.6 \mathrm{~Hz})$, each integrating for one proton, centered at $\delta=8.07$ and $\delta=8.15$ could be assigned to the two $o$-coupled aromatic protons, located at $\mathrm{C}-7$ and $\mathrm{C}-8$ of the anthraquinone system. A one proton singlet at $\delta=8.54$ was attributed for another aromatic proton at C-5. A singlet integrating for three protons at $\delta=2.62$ indicated the presence of a methyl group. The relatively deshielded nature of this methyl group indicated that it might be the part of an acetyl group attached to the aromatic ring at C-6. On these NMR data compound (3) could be proposed as 6-acetyl-2,3-dihydroxy anthacene9,10-dione.

Compound (4) was obtained as gummy material. It appeared as a dark quenching spot on the TLC plate under UV light at $254 \mathrm{~nm}$ and was soluble in $\mathrm{CH}_{2} \mathrm{Cl}_{2}$ and $\mathrm{CHCl}_{3}$. The ${ }^{1} \mathrm{H}$ NMR spectra of compound (4) was given in the experimental part. On this basis of the NMR spectroscopic data, the compound (4) was identified as 2-hydroxy-3methoxy-2,9-dimethyl-1,2-dihydrotetraphene-7,12-dione.

\section{Acknowledgement}

The authors wish to thank the Bangladesh Council of Scientific and Industrial Research under Ministry of Science and Information \& Communication Technology, Government of the Peoples' Republic of Bangladesh.

\section{References}

1. Saha, A., K.K.Chowdhury, S.C.Bachar, S.C.Roy and J.K. Kundu, 2005. Anti-inflammatory, analgesic and diuretic activity of Polygonum lanatum. Pak. J. Pharm. Sci., 18, 1318.

2. Fukuyama, Y., T.Sato, I.Miura, Y.Asakawa and T.Takemoto, 1983. Hydropiperose, a novel coumaryl glycoside from the root of Polygonum hydropiper. Phytochemistry, 22, 549-552.

3. Fukuyama, Y., T. Sato, I. Miura, Y. Asakawa and T. Takemoto, 1982. A potent cytotoxic warburganal and related drimane-type sesquiterpinoids from Polygonum hydropiper. Phytochemistry, 21, 2895-2898.

4. Ahmed, M., M.Khaleduzzaman and M.A.Rashid, 1988. Chalcone derivatives from Polygonum lapathifolium. Phytochemistry, 27, 2359-2360.

5. Kim, H.J., E.R. Woo and H.Park, 1994. A novel lignan and flavonoids from Polygonum aviculare. Journal of Natural Products, 57,581-586.

6. Al-Hazimi, H. M. A. and S. N., Haque, 2002. A new napthoquinone from Polygonum aviculare. Nat. Prod. Lett., 16, 115-118. 